TITLE:

\title{
Measured-loss analysis of superconducting power transmission cable
}

\section{AUTHOR(S):}

Hoshino, T; Yamaji, N; Muta, I; Nakamura, T; Higuchi, N; Natori, N; Fuchino, S; Arai, K

\section{CITATION:}

Hoshino, T ...[et al]. Measured-loss analysis of superconducting power transmission cable. IEEE TRANSACTIONS ON APPLIED SUPERCONDUCTIVITY 2000, 10(1): 1223-1226

\section{ISSUE DATE:}

2000-03

URL:

http://hdl.handle.net/2433/39939

\section{RIGHT:}

(c)2000 IEEE. Personal use of this material is permitted. However, permission to reprint/republish this material for advertising or promotional purposes or for creating new collective works for resale or redistribution to servers or lists, or to reuse any copyrighted component of this work in other works must be obtained from the IEEE. 


\title{
Measured-loss Analysis of Superconducting Power Transmission Cable
}

\author{
Tsutomu Hoshino, Norifumi Yamaji, Itsuya Muta, Takotsune Nakamura, \\ Graduate School of Enginoering; Kyoto University, Sakyo-ku, Kyoto 606-8501, Japan \\ Noboru Higuchi, Naotake Natori, Shuichiro Fuchino and Kazuaki Arai \\ ElectroLechnical Jaboratory, Ibaraki 305-8508, Japan
}

\begin{abstract}
In the former work [6], the eddy current losa in the former due to pitch difference between current conductor and shield conductor whs studied. The calculated value was negligible small which does not explain the measured value. The eddy current loss due to radial component of the magnetic field become comparable with the measured value.

In this paper, the reason of the increased loss is revealed. The disturbance of the conductor piteh yields different strength of the axial magnetic field. The difference of the axial flux toward the radial direction as the radial component of tho flux. Tho flux causes eddy current loss in the copper for stabilizer. It is well match with the measurcd value.
\end{abstract}

\section{INTRODUClioN}

Recontly somo olcctric powar companies began to fabricate the singlo-phase power eable core witl high $\mathrm{Tc}$ stperconducting tapes. Their first target is $66 \mathrm{kV}$, $500 \mathrm{MVA}$ class superconducting powor transmission line cooled with sub-cooled liquid-nitrogen.

The authors made five $10 \mathrm{~m}$-long $\mathrm{Nb}_{3} \mathrm{Sn}$ superconducting power transmission cables in the $1980 \mathrm{~s}[1,2]$. Curront tests of those cables were carried out cooled with liquid or supercritical helium. Cablo conductors consist of two layers of helical-wound tapes, one for transport curront. and another for shield. Electrical insulation consists of wrapped plastic tapes. Countormeasure against thermal contraction is one of the major factor's in the design of this type of the cables, cspocially when superconducting matorials in use arc brittle.

The latest cable "N" is designed to suppress the stress inside the cable caused by thermal contraction, with a conpromise between idoal design and restriction of cable assembly, $\triangle \mathrm{C}$ losses of the latest cable " $\mathrm{N}$ " are reduced to about $1 / 5$ to $1 / 10$ of that of the other cable. Nevertheless, they were ten times larger than those of material tapos wore.

To investigate tho causes of tho higher $\mathrm{AC}$ losses in cable, cable " $\mathrm{N}$ " was clisassembled after the AC loss mea-

Manuscript received September 27, 1909.

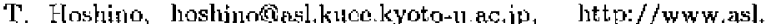
kuco.kyoto-u.ac.jp; I. Muta, muta@knce,kyoto-lu.ac.jp surement. The cable " $\mathrm{N}$ " is fice from such degradation.

In this paper, wo describe ourent distribution analysis of the cable and cquivalent magnotic fiold analysis.

\section{DESIGN OF THL CABIJES}

Cables are composed of two layers of conductors, ono for the transport of current, the other for the shield current to roduce edidy current losses in the cooling channels [3] as stown in Fig. 1. The conductor tapes and insulator in the cable are to be helically wonnd at appropriate lay angles, For the conductor tapes, the most appropriate lay angles are defined by the following equation.

$\tan \psi_{2} / R_{2}=\tan \psi_{1} / R_{1}$

where $R_{1}, R_{2}$ arc radius of shield and transport conductor, $\psi_{1}, \psi_{2}$ are lay angle of shield and transport conductor, respectively. If conductors are wound on this condition, tho magnetic flux density at the center of the cable becomes zero. The cddy current losses inside the transport conductors can be eliminated. The dimensions of cable "N" are shown in Table I.

\section{ANALYSIE OF MAGNEIIO FIELD AND EDDY CuRRFNT Loss}

\section{A. Axial component of the magnetio field}

Assuming that the shield conductor fed counter current of the transport conductor current, Ampère's law tells us

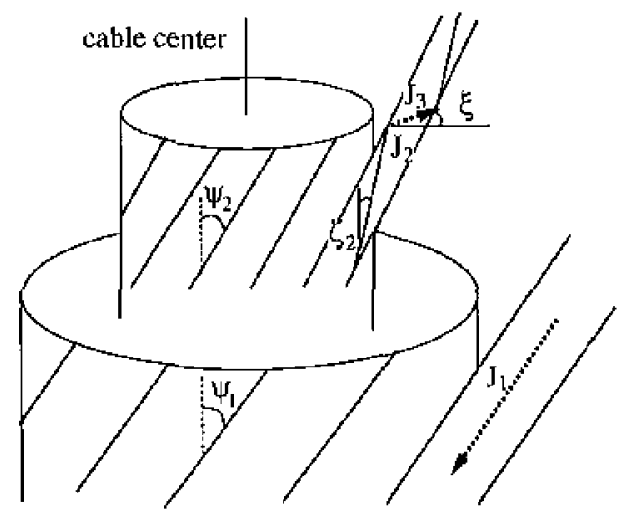

Fig. 1. Lay artglos of the cab]e. 


\begin{tabular}{|c|c|c|c|c|c|}
\hline \multirow{2}{*}{$\begin{array}{c}\text { No. of } \\
\text { layers }\end{array}$} & \multirow{2}{*}{$\begin{array}{l}\text { contents and matorials } \\
\text { former, sUS corrugate tube with SUS mesh }\end{array}$} & \multirow{2}{*}{27.0} & \multicolumn{2}{|c|}{ direc. $\&$ pitch } & \multirow{2}{*}{$\begin{array}{c}\text { thipe size } \\
\text { thesnes } \times \text { wirlth } \\
(\times \text { pieces })\end{array}$} \\
\hline & & & & & \\
\hline $2-8$ & diameter adjuster, tyvek & 28,6 & $\mathrm{~J}, \mathrm{H}$ & 124 & $0.125 \times 70$ \\
\hline 9 & stabilizer performed OI'HC tape & 29.4 & RII & 250 & $0.3 \times 6.5 \times 13$ \\
\hline 10 & - & 30.0 & $\mathrm{I}+\mathrm{H}$ & - & - \\
\hline 11 & superconductor, $\mathrm{Nb}_{3} \mathrm{Sn}$ tape & 30.24 & RII & - & $0.12 \times 6.45 \times 13$ \\
\hline $12-21$ & insulator, lyvek & 32.24 & T.II & 112 & $0.125 \times 70$ \\
\hline $22-75$ & -, every 6 layer & & RH/LH & 70 & $0.125 \times 27 \times 2$ \\
\hline $76-80$ & - & & LH & - & - \\
\hline $81-85$ & - & 45 & $\mathbf{L H}$ & 69 & $0.125 \times 59$ \\
\hline 86 & superconductor, $\mathrm{ND}_{9} \mathrm{Sn}$ tape & 45.34 & $\mathrm{RH}$ & 250 & $0.17 \times 5 \times 23$ \\
\hline 87 & stabilizer performed OFIIC tape & 45.94 & LH & - & $0,3 \times 6,5 \times 19$ \\
\hline 88 & - & 46.54 & $\mathrm{RHI}$ & - & - \\
\hline $89-93$ & insulator, tyvek & & LII & 66 & $0.125 \times 59$ \\
\hline $94-117$ & -, every 6 layer & & RH/LH & 70 & $0.125 \times 27 \times 2$ \\
\hline 118 & - & 52,6 & RLI & - & - \\
\hline $119-120$ & - & & & & $0.125 \times 27 \times 1 / 2$ \\
\hline
\end{tabular}

that there is no $\theta$ direction magnetic fiold in cylindrical coordinates $(r, \theta, z)$. The current $-I$ through the shield conductor flows innor surface along with the lay angle $\psi \mathbf{L}$. Tho (surface) current density $J_{1}$ was exprossed as follows

$I=-J_{1} \cos \psi_{1}\left(2 \pi R_{1}-N d_{1}\right)$

where $N_{1}$ is the number of shield conductor tapes and $d_{1}$ is the gap between shield conductor tapos.

Define $\zeta_{2}$ as the direction of outer surface current density $J_{2}$ through the transport conductor, $\xi$ as the direction of inmer surface current density $J_{3}$ through the transport conductor. The relation

$$
\begin{aligned}
& J_{2} \sin \left(\psi_{2}-\zeta_{2}\right)=J_{3} \cos \left(\psi_{2}+\xi\right) \\
& I=J_{2}\left(2 \pi R_{2 o}-N_{2} d_{2}\right) \cos \zeta_{2} \\
& \quad+J_{2}\left(2 \pi R_{2}-N_{2} d_{2}\right) \frac{\sin \left(\psi_{2}-\zeta_{2}\right)}{\cos \left(\psi_{2}+\xi\right)}
\end{aligned}
$$

is obtained. Where $N_{2}$ is the nutnber of transport conductor tapos, $d_{2}$ is the gap between transport conductor tapes, $R_{2 w}, R_{2 i}$ are outer and inner radius of transport conductor.

Analyzed magnotic ficld are described in the former work [6]. When the pitch of the transport conductor is not equal to that of tho shield conductor, the axial magnetic field within the transport concluetor described as follows:

$$
\begin{aligned}
H_{z i} & =J_{2} \frac{\sin \left(\psi_{2}-\zeta_{2}\right)}{\cos \left(\psi_{2}+\xi\right)} \\
& \times\left\{\cos \xi-\frac{N_{2} d_{2} \sin \psi_{2} \sin \left(\psi_{2}+\xi\right)}{2 \pi R_{2 i}}\right\}
\end{aligned}
$$

Then the eddy current loss $P_{c}$ in the copper stabilizer is expressed as

$P_{e}=\mu_{0}^{2} d_{s}^{3} w_{s}^{3} N_{s} \omega^{2} H_{z i} \cos \psi_{s} /\left\{32 \rho\left(d_{s}^{2}+w_{s}^{2}\right)\right\}$

where $\omega$ is the angular velocity of the current, $d_{s}, w_{s}$ $N_{s}, \psi_{s}, \rho$ are thickness, width, number, lay angle and resistivity of the stabilizer, respectivoly.

\section{B. Rodial component of the magnetir field}

As shown in Fig. 2, $I$ is the current through the transport conductor, $l_{1}$ and $l_{2}$ are the winding pitch of the trunsport conductor and the shield conductor respectively. The radial component of the magnetic field is described ats follows,

$H_{z}(r)= \begin{cases}-I / l_{2} & \left(R_{2}<r<R_{3}\right) \\ I / l_{1}-I / l_{2} & \left(R_{1}<r\right)\end{cases}$

where, $R_{1}$ is inner diameter of transport conductor, $R_{2}$ is outer diameter of shield conductor, $R_{3}$ is inner diameter of shield conductor. If therc is pitch difference between region $A$ and region $B$, there is difference of axial flux density. The difference of axial fux become radial conponent, because of continuity of the flux as shown in Fig. 2. The relations between fiux are doscribed as follows;

$\Phi_{1 \mathrm{r}}=\Phi_{1 \mathrm{~A}}-\Phi_{\mathrm{B}}$

$\Phi_{\mathrm{Br}}=\Phi_{3 \mathrm{~A}}-\Phi_{3 \mathrm{~B}}+\Phi_{1 \mathrm{r}}$

The flux $\Phi_{1 r}$ and $\Phi_{3 r}$ through tho butt mp of superconducting tapes. Assuming that tho radial flux distribution doscribes as a function of Gaussian distribution as follows

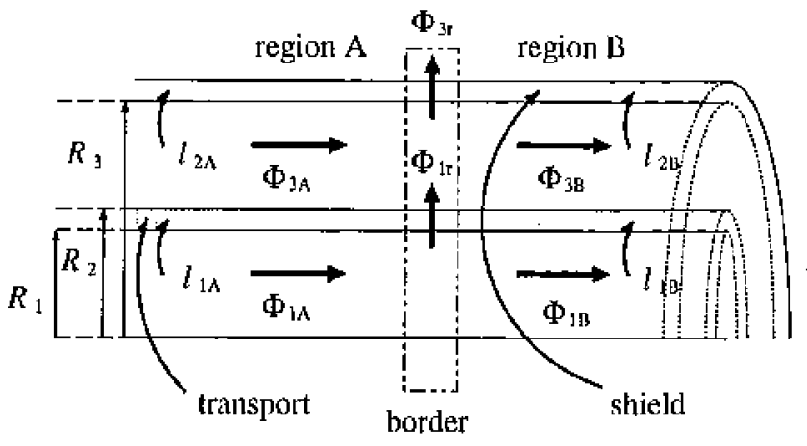

Fig. 2. Flux now ix tho sirglo phase cable 
TA BII,F II Measurcd Pitches of the Cablo "N"

\begin{tabular}{|c|c|c|c|c|c|c|c|c|}
\hline \multirow[b]{2}{*}{ Iayor } & \multicolumn{2}{|c|}{$2 \mathrm{~m}$ point } & \multicolumn{2}{|c|}{$4 \mathrm{~m}$ point } & \multicolumn{2}{|c|}{ is $\mathrm{m}$ point } & \multicolumn{2}{|c|}{8 In point } \\
\hline & $A$ & B & $A$ & $\mathrm{~B}$ & $\mathrm{~A}$ & 13 & $A$ & $\mathrm{~B}$ \\
\hline onter layer of 1 st insulator & 121 & - & 120 & - & 120 & $\cdots$ & 120 & \\
\hline 1st layer of inuer copper & 248 & 240 & 251 & 249 & 250 & 250 & 255 & 250 \\
\hline 2nid layer of inner copper & 247 & 255 & 249 & 251 & 248 & 250 & 249 & 250 \\
\hline inner NbsSn & 249 & 246 & 248 & 247 & 250 & 249 & 254 & 246 \\
\hline 10th leyer of $2 \mathrm{nd}$ insulator & 102 & 104 & 101 & 102 & 102 & 102 & 102 & 102 \\
\hline 59 th layer of $2 \mathrm{ndi}$ insulator & 64 & - & 63 & - & 64 & & 64 & - \\
\hline outer layer of 2nd insulator & $6 x$ & 68 & 69 & 69 & 60 & 68 & 69 & 68 \\
\hline onter $\mathrm{Nb}_{3} \mathrm{Sn}$ & 248 & 253 & 252 & 253 & 246 & 250 & 250 & 247 \\
\hline 1st layer of outor copper & 251 & 248 & 253 & 251 & 252 & 250 & 249 & 251 \\
\hline 2nd hayer of outer copper & 250 & 248 & 252 & 250 & 252 & 251 & 251 & 250 \\
\hline 5th layer of 3rol insulator & 67 & 67 & 66 & 67 & 67 & 67 & 67 & 66 \\
\hline onter layer of $3 \mathrm{rd}$ inisulator & 6.3 & - & 64 & - & 60 & - & 62 & - \\
\hline
\end{tabular}

$f(z)=\frac{1}{R_{1}} \operatorname{cxp}\left\{\frac{-\pi\left(z-z_{0}\right)^{2}}{R_{1}^{2}}\right\}$

with longth $R_{1}$ or $R_{3}$ which is same as conductor radius. Under the condition the flux density is loss than lower critical fiold of $\mathrm{Nb}_{3} \mathrm{Sn}$, there is no radial component flux in the conductor. Using this formula, the eddy current loss in the inner copper layer is obtained. Similarly, the flux $\Phi_{3 r}$ givos the oddy current loss in the outer copper layer.

\section{Evaluation of Edoy Currant Loss}

Mensured pitchos of the cable " $\mathrm{N}$ " aro listed in $\mathrm{TA}$ BLE II. The pitches were measured during assembly and disassembly after all tests. Tho pitch distribution of the conductor after all tests are shown in Fig. 3. Substituting the values of $\mathrm{Nb}_{5} \mathrm{Sn}$ superconductor pitehes to the equation (6) for each pitch sottion, the oddy current loss in

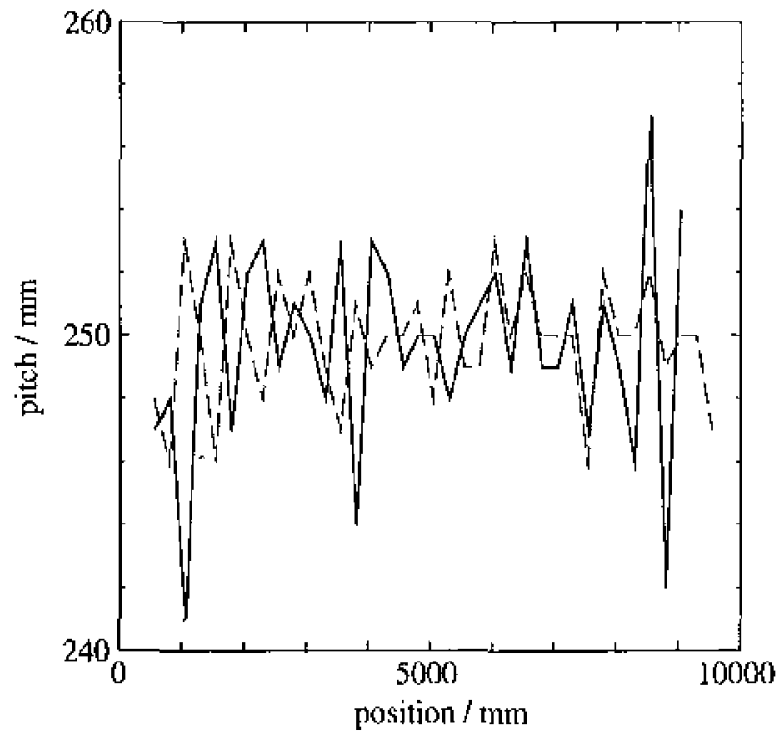

Fig. 3. Pitch distribution of cable "N", solid line: condurtor gltch, broken line: shiclal pitch. the formor dne to axial fhux is negligiblo small as ylown in Eig. 4. Assuning that the rosistivity of tho copper for stabilizer is $\rho=1.6 \times 10^{-10} \Omega \mathrm{m}$, the eddy current loss in innor copper and outur copper obtained, Short sample AC loss values are also indicatid. All values are convorted to one neter cable basc. (short sample AC loss of transport conductor) is proportional to (transport current) ${ }^{3.37}$, and (short samplo $\mathrm{AC}$ loss of shield concluctor) is proportional to (transport current) ${ }^{2.80}$. (eddy current loss) is proportional to (transport eurrent) ${ }^{2}$, but tho odely current loss in tho copper is neglected (not inclicatod in the fignor), no smaller than $10^{-3} \mathrm{~W} / \mathrm{m}$.

The mensured pitches wero distributod with the standard doviation listed in TABLL' III. The pitch difference of the two superconducting layers ate shown in Pig. 5 . The axial fhux shall chango its dircetion to radial circotion. The radial flux makes eddy current on the surface of the stabilizor and conductor and changes the direction $\zeta_{2}$ of surface current $J_{2}$, Substituting the values of $\mathrm{Nb}_{3} \mathrm{~S}_{11}$

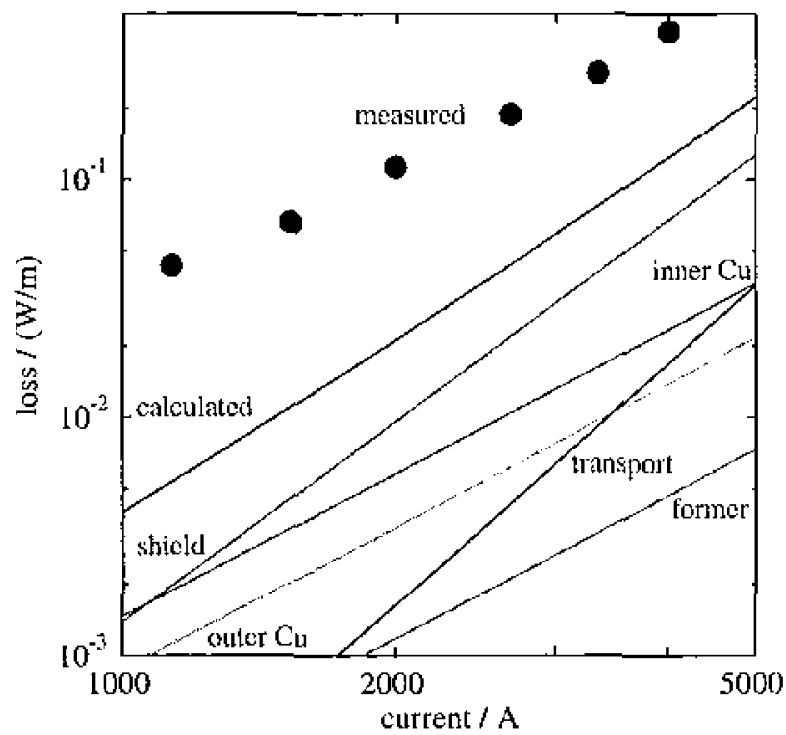

Fig. 4. Measurert and celkulatod loss of cable "N". 
TARJE III

Tile Standaro Deviation of Meastirbo Pitchfs.

\begin{tabular}{|c|c|c|c|}
\hline \multirow[b]{2}{*}{ layyer } & \multicolumn{2}{|c|}{ asemiblo } & disassemble \\
\hline & set 1 & set 2 & set 1 \\
\hline 1st laye: of inner copper & 2.39 & $\overline{1.93}$ & 0,55 \\
\hline 2nd layer of inner copper & 2.17 & 1.91 & 1,97 \\
\hline inner $\mathrm{Nb} \mathrm{b}_{3} \mathrm{~S}_{11}$ & 2.04 & 2,03 & 1.94 \\
\hline outer $\mathrm{Nb}_{3} \mathrm{~S}_{11}$ & 1.87 & 1,73 & 3.28 \\
\hline 1st layer of outer copper & 1.66 & 1.56 & 1.77 \\
\hline 2nd layer of outer copper & 1.56 & 1.75 & 1.44 \\
\hline
\end{tabular}

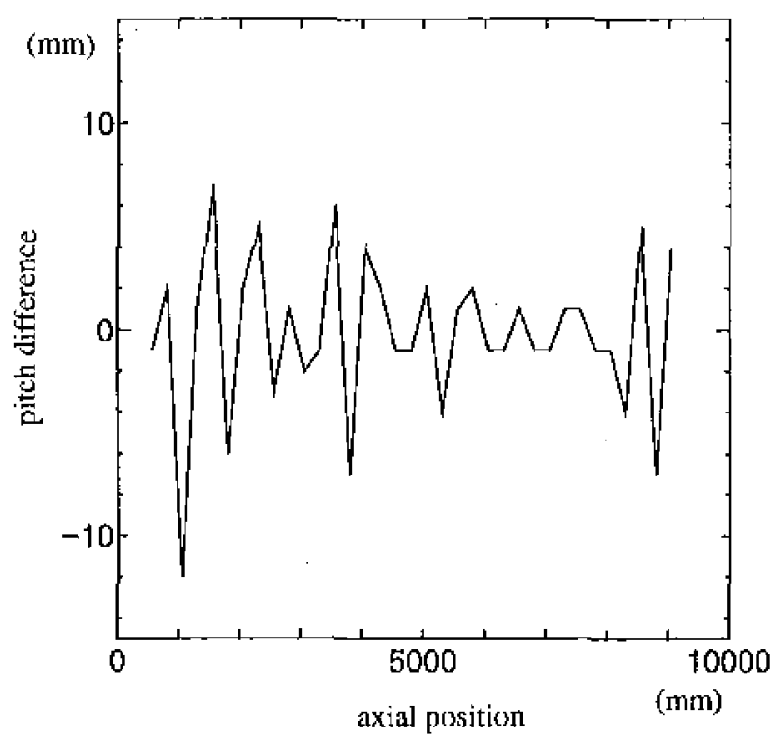

Fig. 5. Pilch Difference Distribution of the Superconducting Layers.

superconductor pitches to the equation (7), (10) for each pitch section, the eddy current loss in the copper layor due to radial flux obtained en shown in Fig. 4. In Fig. 6, the relationslup between the current direction $\zeta_{2}$ on the outer surface $J_{2}$ of inner superconductor and oddy current loss $P_{e}$. The loss was calculated as peak current density is 500 $\mathrm{A} / \mathrm{cm}$. The loss of $1.5 \times 10^{-2} \mathrm{~W} / \mathrm{m}$ corresponds to the 8.7 \% deviation of $\zeta_{2} / \psi_{2}$ which is comparable to the loss of short sample test.

\section{CONCIUSION}

The eddy current loss in the former and the stabilizer was calculated using the disnssombled data of cable "N". The pitch effect of the difference between transport layer and shield layer was onc-tonth ordor of the material tape loss. The pitcl difference is not a dominant reason to increase the $\mathrm{AC}$ loss.

From a viewpoint of the current distribution, the curront flow direction on the outer surfaco of the transport conductor affects remarkably on the eddy current loss. The difference of axial flux yidds radial flux and change the current direction from lay angle of the conductor tape at 8.7 percent.

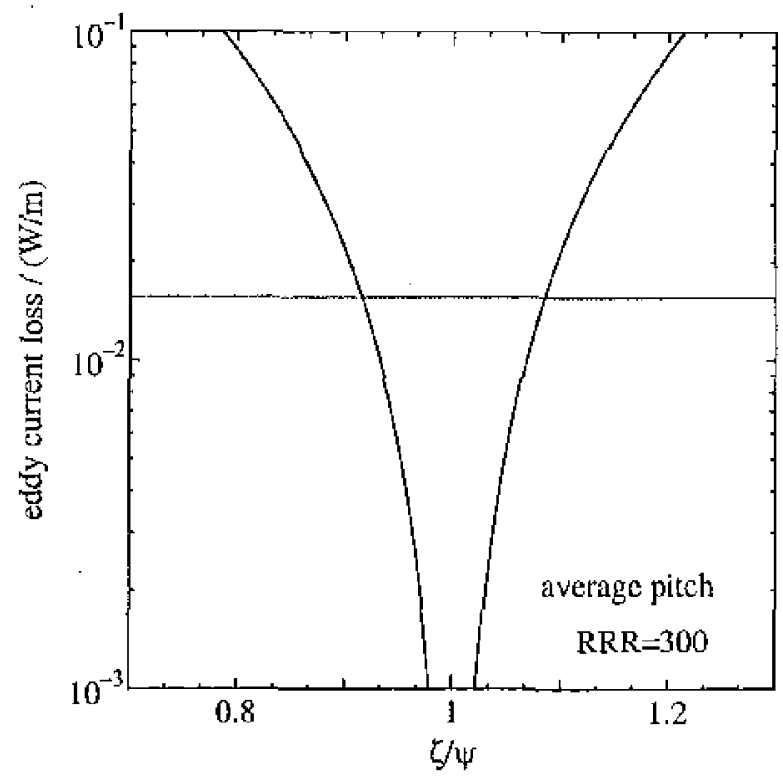

Fig. 6. Relationship betwoen curront dircetion on the outer surface of inner superconductor and eddy curcont losis.

The mechanism of the radial flux genoration is revealed in this paper. The sum up calculatod loss is $1 / 5$ of the measured loss. The remaining (not cvaluated) loss is the eddy current loss of the metals clad on superconducting tapo. The remaining difference shows us to reduce way with manufacturing scheme.

\section{REFERENCES}

[1] N. Higuchi, N. Natori, K. Arai, and 'T'. Hoshino, "Nb3Sn Stperconducting Power 'Tiansmission Cablc," International Sympositum an Neu Develapmentis in Applied Stperconduclivity, World sciontific, pp. 668-673, 1988

[2] K. Arai, N. Natori, N. Figuchi, and 'I'. Foslino, "AC Loss Characteristics of Superconducting Fower Transmission Cable, 11th International Conference on Magnet Technology, Flsavier Applied Seloneo, pp. 185-490, 1080.

(3) J. Sutton, and D. A. Warel, "Design of flcxible Coaxial Cores for AC SC Cables," Onyogrnics, vol. 47, pp. 495-500, 1977.

(A) E. B. Forsyth, R. A. Thomas, "Perfomance Summary of the Brookhaven Superconducting Power Transmission System, "Cryogenies, vol, 26, pp. 599-614, 1986 .

[5] T. Hoshine, M. Shibayama, S. Itol, I. Muta, N. IJignehi, N. Natori, S. Fuchino and K. Arai, "Conductor Pitch Effect on an Eddy Curreatt loss of the Sujerconducting Power Cable Using the Disasiembled Cable "M" Data," Proceedings of the Seventteenth Intemational Cryogenic thigineering Conference, pp. 375 378 , July 1998

[t] T. Hoshino, N. Shlubayma, S. Itoh, I. Muta, N. IHigucli, N. Natori, S. Fuchino, K. Arai, "Conductor Pitch E'fiect on ant Fdely Curent Loss of tho Superconducting Power Cable Using the Dishssombled Gable "N" Data" JEHW Thnsantions on Applied Superconductivity, wol. 9, no. 2, [p, 1277 - 1280 June 1990.

[7] S. Ito, T. Hashino, N. Yamaji, I. Muta, Radial fux componenl. caused by pitel difference of suporconducting power transmission cable " The 6oth Meeting of Cryogentios and SupercondacLivity, F1-11, pp. 12d, June 1999 